\title{
NEUROMUSCULAR BLOCK BY NEOMYCIN IN THE CAT
}

\author{
Citngaruh Lie, Dexis Chen, Angeline Bannes, and Ronald L. Katz*
}

Nromycax has been reported to cause death by respiratory paralysis and to enhance the neuromuscular blocking effect of d-tubocurarine. ${ }^{1-3}$ Suggested mechanisms by which neuromuscular block is produced have included chelation of calcium, ${ }^{4-1 ;}$ as well as competition with calcium. ${ }^{\text {i- } \rightarrow}$ Curare-like activities have also been suggested. ${ }^{\top}$ The site of action of neomycin is probably both pre- and postjunctional. The neuromuscular block has been antagonized by calcium and by' neostigmine. ${ }^{1-\pi, 8-10}$

The literature, however, has offered no satisfactory explanation of the high mortality rate of the patients suffering from neomvcin-induced paralysis. The bizarre time course of the clinical occurrences ${ }^{10}$ suggests that neomycin-induced neuromuscular block may have some peculiar characteristics which have not been identified. We therefore examined the neuromuscular block induced by neomycin in cletail.

\section{Methons}

Eleven healthy cats weighing $2.4-3.6 \mathrm{~kg}$ were anaesthetized with pentobarbitone 40 to $50 \mathrm{mg} / \mathrm{kg}$ intraperitoneally. One common carotid artery, one external jugular vein and the trachea were cannulated. Arterial blood pressure wals recorded continuously. The lungs of all cats were ventilated with air by a Harvard pump delivering a tidal volume of $15 \mathrm{ml} / \mathrm{kg}$, at a frequency of 18 times per minute. The sciatic nerve was severed and stimulated distally with supramaximal scuare pulses of $0.1-\mathrm{ms}$ duration. The tibialis anterior muscle was detached from its insertion and attached with heav silk to a Crass FT 10C force transducer. The force of contraction of the muscle was recorded on an oscillographic ink-recorder. In four cats, cxperiments were performed simultancously on both legs for comparison of time courses of block with and without tetanic stimulation. Neomycin sulfate solution ( $20 \mathrm{mg} / \mathrm{ml}$ ) was prepared from powder. Muscle and oesophageal temperatures were maintained at $36 \pm 0.5^{\circ} \mathrm{C}$.

A baseline tension of $40-50 \mathrm{gm}$ was applied to the muscle. A 5 -second tetanus $(50 \mathrm{~Hz})$ was elicited to set the preparation and to test its stability. If the baseline tension was altered by this manoeuvre, it was restored to $40-50 \mathrm{gm}$. Another tetanus was then elicited. When the baseline tension had been stabilized, which usually followed the first adjustment, the preparation was allowed to stabilize further until

${ }^{\circ}$ Department of Anaesthesiology (UCLA), Harbor Gencral Hospital Cimpus, Torrance, California 90509 .

Rescarch conducted at Anaesthesia Laboratory, Department of Anacsthesiology, Harloor General Hospital, Torrance, California. Supported in part by CRS Cramt \#C1951.

This paper has been presented in part at the American Society of Anaesthesiologists Meeting (Chicago), October 11-15, 1975. An abstract has appeared in its monograph Abstracts of Scientific Papers. P. 199-200. 
the twitch response became constant, taking 30-45 minutes if necessary. Another tetanus was then elicited. If that tetanus, as well as the twitch, equalled the previous tetanus or twitch, these values were taken as control.

A twitch was elicited every 10 seconds $(0.1 \mathrm{~Hz})$, interrupted only for recording of responses to train-of-four, tetanic, and $1 \mathrm{~Hz}$ stimuli. Train-of-four twitches were elicited by $2 \mathrm{~Hz}$ train of stimuli. Tetanus was elicited by $50 \mathrm{~Hz}$ train of stimuli. Ten seconds were allowed to elapse before one frequency of stimulation was changed to another with the exception that the first post-tetanic twitch was elicited as soon after the tetanus as possible.

Neomycin sulphate was injected intravenously. Five hundred mg neomycin sulphate is equivalent to $350 \mathrm{mg}$ neomycin base. All doses quoted refer to the sulphate. Increments were injected repeatedly, each incremental dose being given immediately after the peak response to the preceding dose had been achieved. Cumulative dose-response curves were constructed on log-probit paper. The ED50 and the ED95 were estimated by the method described by Dolon, Ali and Savarese. ${ }^{11}$ After initial recovery, more neomycin was injected as needed to repeat the block for examinations of train-of-four, tetanic, and other responses.

Ability to antagonize the block was tested with edrophonium chloride 0.2 $\mathrm{mg} / \mathrm{kg}$, neostigmine methylsulfate $0.08 \mathrm{mg} / \mathrm{kg}$, pyridostigmine bromide $0.4 \mathrm{mg} /$ $\mathrm{kg}$, calcium chloride $10-50 \mathrm{mg} / \mathrm{kg}$ or germine monoacetate $0.5 \mathrm{mg} / \mathrm{kg}$, injected intravenously to a 70 per cent block. When more than one antagonist was tested on the same cat, the time intervals were at least one hour after edrophonium, and one and a half hours after neostigmine or pyridostigmine. No other drugs were given after germine or calcium.

\section{RESULTS}

Following intravenous injection of neomycin, neuromuscular block began immediately. No fasciculation was observed. Peak effect after each increment appeared within two minutes. The mean cumulative ED50 was $39 \pm 8 \mathrm{mg} / \mathrm{kg}$ and the mean cumulative ED95 was $59 \pm 10 \mathrm{mg} / \mathrm{kg}$. The duration of block depended on its degree. The mean time required to progress from 10 per cent recovery to 90 per cent recovery was $16 \pm 3$ (S.D.) minutes (Figure 1 ). A total of up to five times the ED95 injected over a period of 3 to 4 hours did not lead to failure of the preparation eventually to recover fully in any cat. The $1 \mathrm{~Hz}$ twitch was approximately twice as sensitive to neomycin as the $J .1 \mathrm{~Hz}$ twitch (compared in five cats). Prolonged application of $1 \mathrm{~Hz}$ stimulation did not result in a delayed block or in a secondary block after initial recovery in each of four cats observed for 1 to 2 hours.

After recovery from the initial block by intravenous neomycin 50 to $100 \mathrm{mg} / \mathrm{kg}$ of the drug was injected intraperitoneally. Following this, the onset of neuromuscular block was detected in 10 minutes. Peak effect occurred in approximately 30 to 60 minutes. Recovery was less than 50 per cent complete in three hours in the two cats observed.

Qualitatively neuromuscular block by neomycin was unique. On repeated examinations, no exceptions to the following characteristics were seen in any cat at 

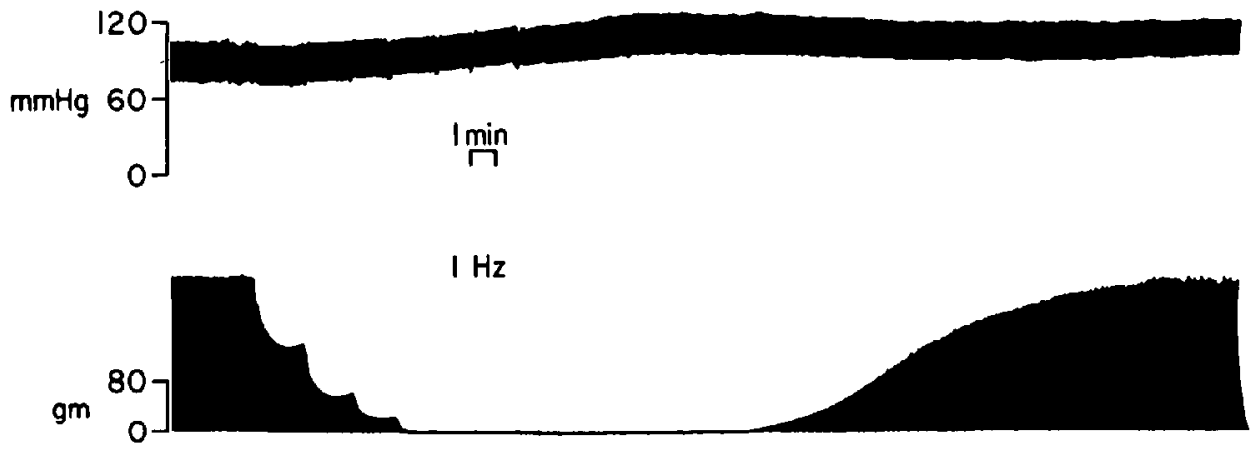

$0.1 \mathrm{~Hz}$

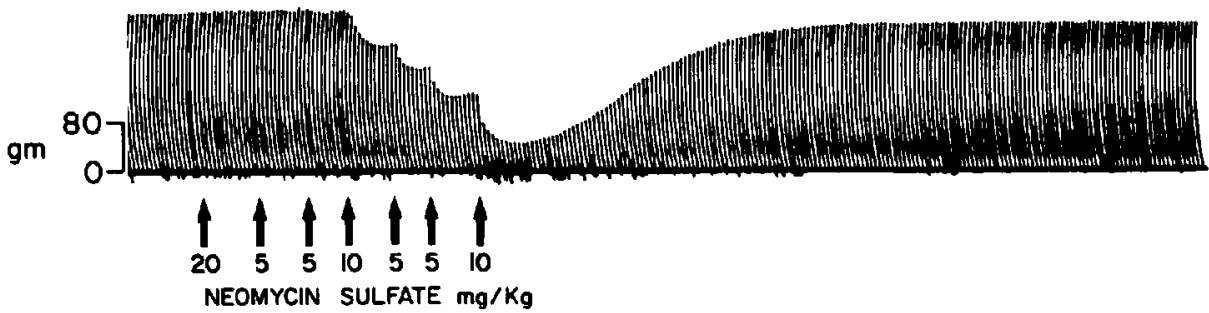

Figune 1. Neuromuscular block by neomycin in the cat observed at two different frequencies of twitch, $1 \mathrm{~Hz}$ and $0.1 \mathrm{~Hz}$. Upper panel: arterial blood pressure. Middle panel: right sciatic: nerve-tibialis anterior muscle preparation; twitch elicited at $1 \mathrm{~Hz}$. Lower panel: identical preparation on the left leg; twitch elicited at $0.1 \mathrm{~Hz}$. Neomycin sulphate was injected at arrows in amounts indicated. Fast twitches increase the sensitivity and therefore the duration of block.

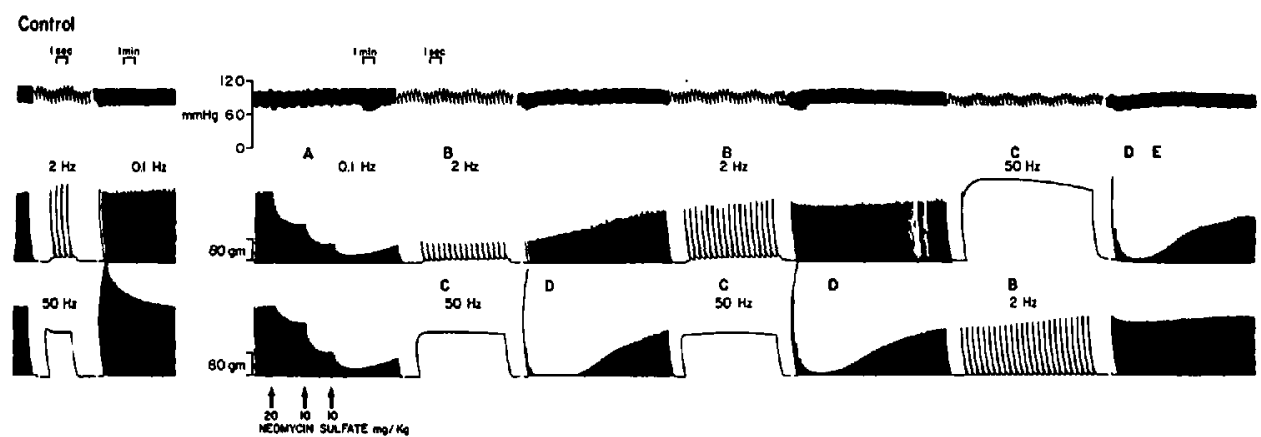

Ficune 2. Neuromuscular blocking characteristics of neomycin in the cat. Upper tracing, arterial blood pressure. Middle tracing, contraction of the right tibialis anterior muscle elicited by stimulation of the sciatic nerve. Lower tracing, simultaneous identical experiment on the left leg. Neonycin sulphate was injected intravenously at arrows. Stimulus frequency was $0.1 \mathrm{~Hz}, 2 \mathrm{Hr}$, or $50 \mathrm{~Hz}$ as indicated. Paper speed was changed during every $2 \mathrm{~Hz}$ and $50 \mathrm{~Hz}$ stimulation as indicated by time scales. Tetanic force $(50 \mathrm{~Hz})$ was recorded on $1 / 5$ scale. Left panel is control. Train-of-four (counting the beginning four responses of a $2 \mathrm{~Hz}$ train of twitches) and tetamus were repeated at approximately 75 per cent block, 25 per cent block, and shortly after recovery of the twitch. Note: (A), immediate onset of neuromuscular block (peak effect: 2 minutes); (B), lack of train-of-four fade $(2 \mathrm{~Hz})$; (C), tetanic force which did not fade $(50 \mathrm{~Hz})$ and did not diminish from control despite block of the twitch; (D) transient post-tetanic facilitation followed by profound post-tetanic exhaustion which delaved the recovery and ( $\mathbf{E}$ ), post-tetanic: exhaustion which persisted after recovery of the twitch. Also note slow development of the tetanic force during block, requiring $0.6 \mathrm{sec}$. at 75 per cent block (1st $\mathrm{C}$ ) rather than a small fraction of a second (control) to reach the maximum. 
any time. Tetanic contractions $(50-100 \mathrm{~Hz}$ ) did not fade (Figure 2, C). Tetanic force remained equal to its control despite depression of the twitch response by as much as 95 per cent (Figure 2, C). Post-tetanic twitches were facilitated for 15 seconds, but the facilitation was followed by marked depression for 5-15 minutes (Fig. 2, D). The post-tetanic depression depended on the degree of block; the more profound the block, the more pronounced the post-tetanic depression. Following a $50 \mathrm{~Hz}$ tetanus of 5 seconds' duration, a 50-80 per cent block invariably' became 100 per cent block for $5-10$ minutes. Longer and repeated tetanic stimulations were followed by more profound post-tetanic depression. The recovery of neuromuscular transmission was thereby delayed. On subsequent resumption of recovery, the post-tetanic depression could be repeated. Even after the twitch had completely recovered for $5-10$ minutes the post-tetanic depression could still be demonstrated (Figure 2, E). On introduction of a tetanic stimulation during profound block, the tetanic force developed slowly. During an 80-9.5 per cent block, the tetanic force required $0.5-9.5$ sec., rather than a fraction of a second as normally required, to reach its plateau, which equaled the control tetanus. If tetanus was continued for more than 10 seconds the tetanic force began to decline steadily from its plateau, resulting in total exhaustion within another $10-30$ seconds. Trainof-four twitches did not fade (Figure 2, B).

Anticholinesterases and calcium antagonized the block. The magnitude of antagonism, however, was unpredictable and incomplete in most instances. Following intravenous injection, edrophonium $(0.2 \mathrm{mg} / \mathrm{kg})$, neostigmine $(0.08 \mathrm{mg} / \mathrm{kg})$, pyridostigmine $(0.4 \mathrm{mg} / \mathrm{kg})$ and calcium chloride $(15-60 \mathrm{mg} / \mathrm{kg})$ restored twitch height from 30 per cent of control to 50 per cent, 70 per cent to 100 per cent, 70 per cent to 100 per cent and 50 per cent to 100 per cent of control values, respectively. The block was completely antigonized in only one of four instances by ncostignine, two of five instances by pyridostigmine, and one of nine instances by calcium. Additional amounts of anticholinesterases slightly improved the incomplete antagonism. Additional amounts of calcium were either ineffective or even self-defeating, restoring part of the block by 5 per cent to 10 per cent with each injection.

Germine monoacetate, $0.5-3.0 \mathrm{mg} / \mathrm{kg}$ completely antagonized any partial block, even with overshoot. With the higher dosage, each single shock to the nerve resulted in a short contracture of the muscle lasting up to one second, both developing and declining slowly. Spontaneous breathing returned in all five cats tested.

\section{Discussion}

Many antibiotics have been reported to block neuromuscular transmission and to enhance the neuromuscular blocking effects of diethyl ether and various neuromuscular blocking agents. ${ }^{1-11 "}$ Pittinger and Adamson, ${ }^{1}$ and Pittinger, Eryasa, and Adamson ${ }^{10}$ have revieved the neuromuscular pharmacology of antibiotics and have emphasized the hazards of antibiotic-induced paralysis under clinical conditions, the mortality being 9 per cent for all antibiotics and 17 per cent for neomycin. ${ }^{11.12 .13}$ The occurrence of antibiotic-induced paralysis was often bizarre. The management was time-consuming. The result was unpredictable and unsatisfactory. ${ }^{+, 10.12}$ These reviewers concluded that neuromuscular block by the strepto- 
mycin-neomycin group of antibiotics was due primarily to their prejunctional effects. The mechanism was probably competition with calcium ions at a common site at the cell membrane of the motor nerve terminal, ${ }^{1}$ thereby inhibiting acetylcholine release.

The competition theory, however, does not explain failure of calcium to antagonize the block completely. Absence of a depletion-dependent delayed block or a secondary block typical of hemicholinium, ${ }^{1+}$ elicitable by continuous stimulation with high stimulus frequency $(1 \mathrm{~Hz})$, suggests that the pre-junctional block produced by neomycin differs in mechanism from the pre-junctional block produced by hemicholinium.

Assuming that the neuromuscular block by neomycin in the cat is qualitatively similar to neomycin-induced paralysis in man, our results may partially explain the bizarre picture observed clinically.

Neuromuscular block by neomycin is characterized by a tetanus which does not diminish in strength despite near complete blockade of the twitch. This suggests the possibility that different neuromuscular blocking agents may not block the twitch and the tetanus equally or in a fixed proportion. Since all physiological muscular activities are the result of partially tetanizing volleys of nerve impulses of various frequencies, ${ }^{15}$ rather than the result of either a discrete twitch or a $50 \mathrm{~Hz}$ tetanus, the severity of neomycin-induced paralysis may not be quantifiable by measurement of either the twitch or the tetanus. In addition, the twitch and the tetanus are difficult to quantify exactly without a rccorded control. ${ }^{16}$ Lack of trainof-four fade makes indirect assessment of the block impossible by the method of Ali, et $a{ }^{1{ }^{1 i}}$ and Lee. ${ }^{17}$ Lack of tetanic fade may lead to a false sense of security, particularly if one assumes that neomycin blocks the neuromuscular transmission "like curare" and if one mistakes fade of tetanus as one of its most sensitive signs of block, or at least characteristic of this type of block.

Post-tetanic exhaustion appears to be the only reliable sign in the differential diagnosis of neomycin-induced neuromuscular block. It is also the most sensitive sign of block because it can still be observed after the twitch has recovered. Unfortunately, the picture may be confused by interactions between neomycin, anaesthetics, other relaxants, and the antagonists like calcium and anticholinesterases used in attempts to reverse the block.

Conceivably, patients suffering from neomycin-induced paralysis may perform a single clinical test, like head-raising, vital capacity, hand squeeze, etc., with a false normal result because the tetanic force does not diminish. This predisposes to premature withdrawal of ventilatory support. Then when the patient strains in distress as the result of such withdrawal of support, repeated tetanic contractions may cause rapid deterioration of the neuromuscular transmission by post-tetanic exhaustion. It is suggested that repeated evaluation of endurance by tests which require continuous performance, such as maximal breathing capacity, may uncover the block by induction of post-tetanic depression.

Successful clinical reversal of the block has been reported but the effectiveness and efficacy of antagonism have not been established. ${ }^{1,10.15 .19}$ Anti-curare effects might have contributed to the apparent clinical success of some of the reported cases, but the high mortality rate attests to the failure of the anti-curare regimen. ${ }^{10}$

The antibacterial action of neomycin is of considerably longer duration than 
the neuromuscular block. Consequently the relatively short duration of the block can not be assumed to be due to elimination of the neomycin. In other words, subclinical paralysis may persist. Accumulation of a large amount or intraperitoneal instillation of a large dose therefore may have a protracted effect. Return of the block is a constant threat because subclinical paralysis could be converted to a profound block with little warning by a spell of strenuous coughing for example.

Germine appears to be a promising antagonist worthy of further investigation. It antagonizes other types of neuromuscular block by causing repetitive firing of the motor nerve terminal as well as of the muscle fibre. ${ }^{20}$ Repetitive firing causes a brief tetanus to result from a single stimulus. As we have observed, repeated tetanus would depress the neuromuscular transmission, rather than improve it. It is possible, therefore, that, despite the post-tetanic depression, as long as the motor terminal liberates enough transmitter by such repeated firing for the muscle fibre to fire one action potential, it will repeat itself to produce a forceful contraction, or the repetitive firing may not be long enough to cause post-tetanic depression.

\section{SUMmany}

The neuromuscular block produced by neomycin is unique. Despite nearly' complete blockade of the twitch the tetanus is not blocked and does not fade. The pathognomonic post-tetanic exhaustion has not been reported previously. Anticholinesterases and calcium antagonize the block, but the antagonism may not be complete. Germine antagonizes the block in the cat, but its clinical value has not been tested. These characteristics of neuromuscular block by neomycin strongly suggest respiratory support and sedation to decrease the respiratory drive, rather than attempts at antagonism, as the rational management of patients suffering from toxic paralysis due to neomycin.

\section{RÉSUMÉ}

Les caractéristiques du bloc neuromusculaire de la Néomycine furent étudiées sur une préparation "nerf sciatique-muscle tibial antérieur" de chat. Le bloc neuromusculatire de la Néomycine ( $\mathrm{ED} 50=39 \pm 8 \mathrm{mg} / \mathrm{kg}$ ) est différent du bloc neuromusculaire de la d-tubocurarine. Les contractions tétaniques ne furent pas diminuées par rapport aux valeurs contrôles malgré la suppression du "twitch." La série de quatre contractions ( $2 \mathrm{~Hz}$ pendant 2 secondes) et le tétanos ( $50 \mathrm{~Hz}$ pendant 5 secondes) ne montrent pas d'évanescence. Les "twitch" (= secousses) posttétaniques furent constamment diminuées et ce d'une façon marquée, à la suite d'une brève période de facilitation post-tétanique d'une durée de 15 secondes. Un bloc de 50 pour cent put ètre transformé en un bloc de 100 pour cent pour 5 à 15 minutes par un tétanos de $50 \mathrm{~Hz}$ d'une durée de 5 secondes. L'antingonisme par les anticholinestérasiques (édrophonium, néostigmine, pyridostigmine) et par le calcium fut incomplet chez la plupart des chats. Le monoacétate de germine antagonise complètement le bloc chez tous les chats testés. Ces résultats peuvent avoir des implications cliniques dans le diagnostic et le traitement des patients atteints de paralysie toxique secondaire à la néomycine et suggèrent que l'assistance respiratoire et la sédation plutôt qu'un anticurare sont des traitements de choix. 


\section{ACKNOWLEDGMENT}

The authors are indebted to Ms. K. Hayes for her untiring secretarial assistance, to Werner E. Flacke, M.D., Department of Pharmacology, University of Arkansas Medical Center, for a generous supply of germine monoacetate, and to Stephen $\mathrm{N}$. Steen, M.D., for lending the recorder.

\section{REFERENCES}

1. Pittincer, C. \& Adamson, R. Antibiotic blockade of neuromuscular function. Ann. Review Pharmacol. 2l: 169 (1972).

2. Stanley, V.F., Giesecke, A.H., \& Jenkins, M.T. Neomycin-curare neuromuscular block and reversal in cats. Anesthesiology 31: 228 (1969).

3. Puidgen, J.E. Respiratory arrest thought to be clue to intraperitoneal neomycin. Surgery 40: 571 (1956)

4. Corrado, A.P. Respiratory depression due to antibiotics: calcium in treatment. Anesth. Analg. 42: 1 (1963).

5. Compado, A.P., Ranros, A.O., \& DeEscobar, C.T. Neuromuscular blockade by neomycin: potentiation by ether anesthesia and d-tubocurarine and antagonism by calcium and prostigmine. Arch. Int. Pharmacodyn. 121: 380 (1959).

6. Adriani, J. Appraisal of Current Concepts in Anesthesiology, IV, St. Louis: Mosby, p. 139 (1968).

7. Elirquist, D. \& Josefsson, J.O. The nature of the neuromuscular block produced by neomycin. Acta Physiol. Scand. 54: 105 (1962).

8. Vital Brazil, O. \& Prado-Franceschi, J. The nature of neuromuscular block produced by neomycin and gentamycin. Arch. Int. Pharmacodyn. Ther, 179: 78 (1969).

9. Pittinger, C.B., Long, J.P., \& Miller, J.R. The neuromuscular blocking action of neomycin: a concern of the anesthesiologist. Anesth. Analg. 37: 276 ( 1958 ).

10. Pittincer, C.B., Enyasa, Y., \& Adanson, R. Antibiotic-induced paralysis. Anesth. Analy. 49: $487(1970)$.

11. Donlox, J.V., Ali, H.H., \& Savarese, J.J. A new approach to the study of four nondepolarizing relaxants in man. Anesth. Analg. 53: 934 (1974).

12. Editorial: Toxicity of neomycin. N. Engl. J. Med. 258: 144 (Jan. 16, 1958).

13. Zauder, H.L. Clinical Anesthesia (Volume 10/1), Pharmacology of Adjuvant Drugs, Philadelphia: F.A. Davis Company. Chap. 13, p. 285 (1975).

14. Schuelen, F.W. The mechanism of action of the hemicholiniums. Int. Review Neurobiol. 2: $77(1960)$.

15. Gurton, A.C. Textbook of Medical Physiology, 4th ed. Philadelphia, London, Toronto: W.B. Saunders Company, p. 89 (1971).

16. Ali, H.H. \& Kitz, R.J. Evaluation of recovery from nondepolarizing neuromuscular block using a digital neuromuscular transmission, analyzer: Preliminary report. Anesth. Analg 52: 740 (1973).

17. LEE, C. Train-of-4 quantitation of competitive neuromuscular block. Anesth. Analg. 54: $649(1975)$.

18. Vital Brazil, O. \& Corrado, A.P. The curariform action of streptomycin. J. Pharmacol. Exp. Ther. 120: 452 (1957).

19. Middleton, W.H., MorGan, D.D., \& Moyers, J. Neostigmine therapy for apnea occurring after administration of neomycin. Report of a case. JAMA. 165: 2186 (1957).

20. Higasili, H., Yonemura, K., \& Shinoji, K. Antagonism of neuromuscular blockers by germine monoacetate, Anesthesiology 38: 145 (1973). 